\title{
The role of diabetes mellitus in localized and metastatic renal cell carcinoma
}

\author{
Sandra Steffens ${ }^{1 \#}$, Christoph von Klot ${ }^{1 \#}$, Hendrik Egggers ${ }^{1}$, Christoph Seidel $^{2}$, Gerd Wegener $^{3}$, \\ Mark Schrader ${ }^{4}$, Markus A. Kuczyk ${ }^{1^{*}}$, Andres J. Schrader ${ }^{4}$
}

\footnotetext{
${ }^{1}$ Department of Urology and Urologic Oncology, Hannover Medical School, Hanover, Germany;

*Corresponding Author: Kuczyk.Markus@mh-hannover.de

${ }^{2}$ Department of Oncology, Hannover Medical School, Hanover, Germany;

${ }^{3}$ Clinical Cancer Registry, Hannover Medical School, Hanover, Germany;

${ }^{4}$ Department of Urology, Ulm Medical School, Ulm, Germany.
}

Received 9 September 2011; revised 16 October 2011; accepted 27 October 2011.

\begin{abstract}
Introduction \& Objectives: Until recently, the incidence of renal cell carcinoma (RCC) has been increasing worldwide, mainly in western countries, at a rate between $2 \%$ and $4 \%$ per year. However, the reason for this dramatic increase in number has not been fully understood. Diabetes mellitus (DM) is a known risk factor for RCC, but the impact of DM on the prognosis of RCC is unclear. In the present study, we investigated the potential influence of DM on clinicopathological features of localized and metastatic RCC. Material \& Methods: We evaluated 863 patients with primary RCC who had undergone renal surgery between 1991 and 2005 in the University Hospital Hannover; the mean follow-up was 58 months. To test the association of DM with survival end-points, Kaplan-Meier Method and Cox multivariable logistic regression models were applied. Results: In total, we identified 123 diabetic patients who suffered from RCC, 9 patients with diabetes type 1 and 114 with type 2 . Patients with DM type 2 presented significantly more often with pT1a tumours at diagnosis (40.0\% vs $31.7 \%, p=0.02)$, had less frequently high grade cancer (G3/4; $10.3 \%$ vs $16.2 \%, p=$ 0.03 ), were older (median, 65.3 vs 61.6 years; $p<$ 0.001 ), and had a higher BMI at diagnosis (median, 27.6 vs $25.8, p<0.001)$. However, there was no difference between diabetic and non-diabetic patients concerning sex, histological subtype, lymphatic and distant metastasis. In addition, there was no discrepancy in 5-year cancer specific survival between both groups $(62.2 \%$ vs $64.9 \%$ for patients with and without DM type 2,
\end{abstract}

\#Both authors contributed equally. respectively). Applying multivariable analysis, unlike age, tumour stage, grade and N/M status, diabetes was not identified as a significant independent prognostic factor. Conclusions: To our knowledge this is the first study to show that even though diabetes is a risk factor for RCC it does not seem to influence its prognoses even though it might be diagnosed earlier in diabetic patients.

Keywords: Renal Cell Cancer; Risk Factor; Diabetes Mellitus; Survival; Prognosis

\section{INTRODUCTION}

More than 40,000 new cases are diagnosed in the European Union every year and more than half of these patients will die from RCC [1]. Worldwide, the mortality from RCC exceeds 100,000 per year [2]. Despite increased health care facilities for imaging and consequent early diagnosis, still up to one third of all patients with RCC will have metastases at time of presentation [3-7]. Of the remaining two thirds, approximately $20 \%-40 \%$ of those treated with (partial) nephrectomy in case of localized disease, will eventually develop metachronous metastasis or locally recurring cancer [8-11].

As patients' clinical courses vary and are difficult to predict, and as an increasing number of adjuvant and palliative agents has been and is currently being developed for the treatment of RCC, the stratifications of patients to different therapeutic strategies according to specific prognostic factors will become increasingly important. Favourable prognostic factors include complete resectability and a long interval between initial diagnosis and development of metastases [12,13].

An increased risk of kidney cancer has been reported for obese persons [14] as well as for diabetic patients 
[15-17]. Moreover, obesity is a major risk factor associated with diabetes mellitus (DM) $[18,19]$. Although the precise mechanism how obesity contributes to insulin resistance and DM has not yet been identified; both DM and obesity are associated with hyperinsulinemia [20]. As the incidence of DM increases with body mass [18, 19,21], and obesity has only recently been identified as an independent positive prognostic factor for patients with localized RCC [22], we investigated the role of DM on the prognosis of RCC.

\section{MATERIAL AND METHODS}

A total of 863 RCC patients treated from 1991 to 2005 by radical nephrectomy or nephron-sparing surgery and information whether they also suffered DM were included in this study. Information on patients' and tumour characteristics such as TNM stage, age and sex, histological differentiation, Fuhrman grade, presence of regional lymph node or distant metastases and type of surgery was obtained from our institutional database (MHH).

The duration of the follow-up was calculated from date of surgery to the date of death or last follow-up. Death was assessed as either cancer-related or unrelated. In case of patients' death, the cause was obtained from death certificates or correspondence with physicians.

Chi-square (or Fisher's exact) and T-tests were applied to evaluate patients' and tumour characteristics of potential importance for the postoperative clinical prognosis (Table 1). The cancer specific survival (CSS) was calculated according to Kaplan-Meier method. Likelihood of Cox proportional hazards regression model was used to compare the prognostic accuracy between the two classifications. SPSS 17.0 was used for statistical assessment. All tests were 2-sided, $p<0.05$ was considered to indicate significance.

\section{RESULTS}

\subsection{Patients' and Tumour Characteristics}

In total, 123 out of 863 patients with RCC were identified as diabetic, 9 patients with DM type 1 and 114 with type 2. To compare homogeneous collectives, we excluded those patients with type $1 \mathrm{DM}$ form all further calculation.

The median age for all 854 patients was 62.1 years and differed significantly between diabetic and non-dia- betic RCC patients (median, 65.3 vs 61.6 years; $p<0.001$, t-test). In addition, patients with DM had a significantly higher median body mass index (BMI) of 27.6 vs 25.8 $\mathrm{kg} / \mathrm{m}^{2}(p<0.001$, t-test). In our cohort, those patients with DM type 2 presented significantly more often with pT1a tumours ( $40.0 \%$ vs $31.7 \%$; $p=0.018, \mathrm{chi}^{2}$ ) and less often with poorly differentiated RCC (G3/4 cancer in $10.3 \%$ vs $16.2 \%, p=0.026, \mathrm{chi}^{2}$ ).
Table 1. Diabetes mellitus (DM) related tumour and patient specific characteristics.

\begin{tabular}{|c|c|c|c|c|}
\hline Variable & DM II & no DM & $p$-value & Test \\
\hline $\begin{array}{l}\text { Age in Years } \\
\text { [mean; } \pm \text { SD] }\end{array}$ & $65.5 \pm 8.7$ & $60.9 \pm 11.5$ & $<0.001$ & t-test \\
\hline $\begin{array}{l}\text { BMI in } \mathrm{kg} / \mathrm{m}^{2} \\
\text { [mean; } \pm \mathrm{SD} \text { ] }\end{array}$ & $28.8 \pm 6.7$ & $26.6 \pm 4.4$ & 0.001 & t-test \\
\hline Histology & & & 0.32 & $\begin{array}{c}\text { Fisher's } \\
\text { Exact }\end{array}$ \\
\hline Clear Cell & 109 (95.6\%) & $680(92.6 \%)$ & & \\
\hline Non Clear Cell & 5 (4.4\%) & $54(7.4 \%)$ & & \\
\hline $\begin{array}{c}\text { Stage } \\
\text { (TNM 2002) }\end{array}$ & & & 0.018 & $\mathrm{Chi}^{2}$ \\
\hline pT1a & 42 (40.0\%) & 222 (31.7\%) & & \\
\hline pT1b & 22 (21.0\%) & $156(22.2 \%)$ & & \\
\hline pT2 & 3 (2.8\%) & $61(8.7 \%)$ & & \\
\hline рТЗа & 7 (6.7\%) & 111 (15.8\%) & & \\
\hline $\mathrm{pT} 3 \mathrm{~b} / \mathrm{c}$ & 28 (26.7\%) & 133 (19.0\%) & & \\
\hline pT4 & $3(2.8 \%)$ & 18 (2.6\%) & & \\
\hline $\begin{array}{c}\mathrm{LN} \\
\text { metastasis }^{1}\end{array}$ & $6(5.3 \%)$ & $61(8.2 \%)$ & 0.35 & $\begin{array}{l}\text { Fisher's } \\
\text { Exact }\end{array}$ \\
\hline $\begin{array}{l}\text { Pumonal/ } \\
\text { Visceral } \\
\text { Metastasis }^{1}\end{array}$ & 18 (15.8\%) & 124 (16.8\%) & 0.89 & $\begin{array}{c}\text { Fisher's } \\
\text { Exact }\end{array}$ \\
\hline Grade & & & 0.026 & $\mathrm{Chi}^{2}$ \\
\hline G1 & $14(13.1 \%)$ & $106(15.3 \%)$ & & \\
\hline G2 & 82 (76.6\%) & 474 (68.5\%) & & \\
\hline G3 & $9(8.4 \%)$ & 110 (15.9\%) & & \\
\hline G4 & $2(1.9 \%)$ & $2(0.3 \%)$ & & \\
\hline
\end{tabular}

${ }^{1}$ at time of renal surgery; ${ }^{2}$ from time of renal surgery; Abbreviations: BMI = body mass index, $\mathrm{DM}=$ diabetes mellitus, $\mathrm{SD}=$ standard deviation, $\mathrm{LN}=$ lymph node.

However, there were no significant difference between diabetic and non-diabetic patients concerning nodal disease $(5.3 \%$ vs $8.2 \%, p=0.35)$ and visceral metastasis $(15.8 \%$ vs $16.8 \%, p=0.89)$ at diagnosis.

\subsection{Cancer Specific Long-Term Survival (CSS)}

After a mean follow-up of 5 years, 336 (39.3\%) patients had died from tumour progression, 40.4 and $39.2 \%$ of all patients with and without DM type $2(p=0.84$, Fishers' exact). With a 5-year-CSS rate of $62.2 \%$ and $64.9 \%$, this difference among groups was not demonstrated to be statistically significant, either ( $p=0.67$, log rank; Figure 1).

In accordance, applying multivariable analysis, unlike age, tumour stage, grade and N/M status, diabetes could not be identified as a significant independent prognostic factor (HR 1.247 (95\% CI 0.89-1.75, $p=0.203$, Cox regression; Table 2).

\section{DISCUSSION}

To our knowledge this is the first study focusing on the association between DM and kidney cancer mortality. 


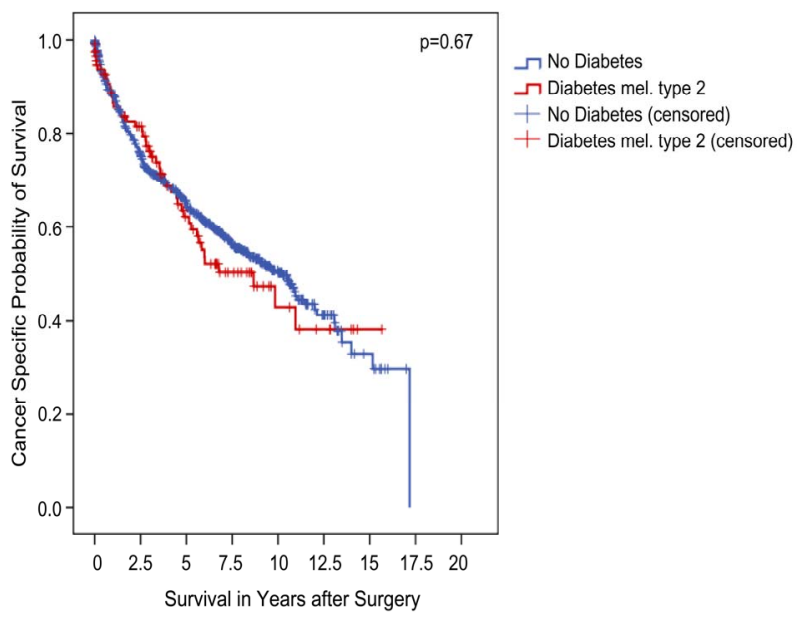

Figure 1. Association between diabetes type 2 and clinical outcome in all patients (Kaplan-Meier; $n=854$ evaluable): the 5 -year CSS was not different between both groups (62.2\% vs $64.9 \%$ for patients with and without diabetes type 2 , respectively; $p=0.67$, log-rank test).

Table 2. Diabetes fails as an independent prognostic marker for cancer specific survival in patients with RCC (multivariable Cox regression analysis).

\begin{tabular}{|c|c|c|}
\hline Variable & HR (95\% CI) & $p$-value \\
\hline Age & $1.04(1.03-1.05)$ & $<0.001$ \\
\hline Sex & & 0.39 \\
\hline Female & Reference & \\
\hline Male & $1.12(0.87-1.44)$ & \\
\hline Grade & & $<0.001$ \\
\hline G1 & Reference & \\
\hline G2 & $1.29(0.85-1.97)$ & 0.24 \\
\hline $\mathrm{G} 3 / 4$ & $2.27(1.38$ - 3.75) & 0.001 \\
\hline Stage & & $<0.001$ \\
\hline pT1a & Reference & \\
\hline pT1b & $1.25(0.84-1.85)$ & 0.27 \\
\hline pT2 & $2.49(1.56$ - 3.97) & $<0.001$ \\
\hline рТЗа & $1.94(1.30-2.91)$ & 0.001 \\
\hline рT3b & $2.20(1.50-3.25)$ & $<0.001$ \\
\hline рТЗс & 7.28 (2.81 - 18.89) & $<0.001$ \\
\hline pT4 & $2.14(1.01-4.18$ & 0.026 \\
\hline LN Metastasis $^{1}$ & & $<0.001$ \\
\hline Negative & Reference & \\
\hline Positive & $2.77(1.93-3.96)$ & \\
\hline $\begin{array}{l}\text { Pumonal/Visceral } \\
\text { Metastasis }^{1}\end{array}$ & & $<0.001$ \\
\hline Negative & Reference & \\
\hline Positive & $2.71(2.01-3.64)$ & \\
\hline Diabetes Mellitus (DM) ${ }^{1}$ & & 0.20 \\
\hline No DM & Reference & \\
\hline DM II & $1.25(0.89-1.75)$ & \\
\hline
\end{tabular}

${ }^{1}$ At time of surgery.
The annual mortality-to-incidence ratio with RCC is significantly higher compared to other urological malignnancies, and its incidence has been increasing steadily in recent decades [23]. Many risk factors may play a role in this increase, including nutritional and hormonal parameters, hypertension, and family history of RCC [16, 24-27]. A history of DM has also been associated with a modest increase in the risk of RCC in several studies [15-17].

This may be mediated through an increase in the incidence of hypertension or body mass [17]. Obesity is another widely accepted risk factor for the development of RCC [14]. Furthermore, in a survey of adults in the United States, overweight and obese individuals had a higher relative risk of hypertension, hypercholesterolemia, and DM, compared with normal weight individuals. In addition, the BMI has only recently been identified as an independent positive prognostic factor for patients with localized RCC [22].

More than 280 million people worldwide are known to suffer from DM (http://www.diabetesatlas.org), and this number is projected to grow to 438 million by 2030 . DM can change the outcome of cancer either directly, through biological mechanisms, or indirectly, by affecting the use of screening and treatment allocation. Whereas the association between DM and pancreatic cancer is fairly well established from studies carried out to date [28], risks of death from cancers at other sites in diabetics are less well understood. However, DM is known to commonly occur together with breast cancer; and two of the major risk factors for type $2 \mathrm{DM}$, similar to RCC, older age and obesity are also associated with breast cancer [29]. In addition, clinical studies suggest an association between DM and an inferior outcome in women with breast cancer [29]. Interestingly, several anti-diabetic therapies, including the biguanides and the peroxisome proliferator-activated receptor ligands may also have activity against breast cancer and are being tested in clinical trials [29].

In this large retrospective analysis with a mean follow up period of 5 years we were able to show that patients with DM type 2 presented significantly more often with smaller tumours at diagnosis (pT1a) and had less frequently high-grade RCC. In addition, we found a significantly higher BMI in diabetic patients compared to those without diabetes. However, we did not reveal an influence of DM on the histological subtype as well as the prevalence of lymph node and distant metastasis at the time of diagnosis. The five-year tumour specific survival was similar in both groups and DM could not be identified as a significant independent prognostic marker applying multivariable analysis.

Previous studies have suggested that the development of renal cell cancer in obese, diabetic patients is related 
to hormonal changes, showing that obese diabetic women have an increased risk of renal cell cancer compared to men [30]. In our study there was no difference between the incidence of RCC in diabetic and non-diabetic men and women.

Our study is not without limitations that need to be acknowledged including its retrospective design, its lack of central pathologic review as well as documentation of specific additional treatment modalities in case of relapse though at least subjectively we do not believe that the latter differed significantly between either groups.

In conclusion, to our knowledge this is the first study showing that even though diabetes is a risk factor for RCC and diabetic patients seem to be diagnosed earlier with RCC (lower stages and tumour grade) it does not influence the prognosis of RCC.

\section{REFERENCES}

[1] Ljungberg, B. (2004) Prognostic factors in renal cell carcinoma. Scandinavian Journal of Surgery, 93, 118-125.

[2] Patel, P.H., Chaganti, R.S. and Motzer, R.J. (2006) Targeted therapy for metastatic renal cell carcinoma. British Journal of Cancer, 94, 614-619.

[3] Golimbu, M., Joshi, P., Sperber, A., Tessler, A., Al-Askari, S. and Morales, P. (1986) Renal cell carcinoma: Survival and prognostic factors. Urology, 27, 291-301. doi:10.1016/0090-4295(86)90300-6

[4] Kozlowski, J.M. (1994) Management of distant solitary recurrence in the patient with renal cancer. Contralateral kidney and other sites. The Urologic Clinics of North America, 21, 601-624.

[5] Pontes, J.E. (1983) Adjunctive treatment of renal cell carcinoma. International Advances in Surgical Oncology, 6, 309-322.

[6] Ritchie, A.W. and De Kernion, J.B. (1987) The natural history and clinical features of renal carcinoma. Seminars in Nephrology, 7, 131-139.

[7] Silverberg, E. and Lubera, J. (1987) Cancer statistics, 1987. CA: A Cancer Journal for Clinicians, 37, 2-19. doi:10.3322/canjclin.37.1.2

[8] Motzer, R.J., Bander, N.H. and Nanus, D.M. (1996) Renal-cell carcinoma. The New England Journal of Medicine, 335, 865-875. doi:10.1056/NEJM199609193351207

[9] Rabinovitch, R.A., Zelefsky, M.J., Gaynor, J.J. and Fuks, Z. (1994) Patterns of failure following surgical resection of renal cell carcinoma: Implications for adjuvant local and systemic therapy. Journal of Clinical Oncology, 12, 206-212.

[10] Sandock, D.S., Seftel, A.D. and Resnick, M.I. (1995) A new protocol for the followup of renal cell carcinoma based on pathological stage. The Journal of Urology, 154, 28-31. doi:10.1016/S0022-5347(01)67215-X

[11] Skinner, D.G., Colvin, R.B., Vermillion, C.D., Pfister, R.C. and Leadbetter, W.F. (1971) Diagnosis and management of renal cell carcinoma. A clinical and pathologic study of 309 cases. Cancer, 28, 1165-1177. doi:10.1002/1097-0142(1971)28:5<1165::AID-CNCR28 20280513>3.0.CO;2-G
[12] Murthy, S.C., Kim, K., Rice, T.W., et al. (2005) Can we predict long-term survival after pulmonary metastasectomy for renal cell carcinoma? The Annals of Thoracic Surgery, 79, 996-1003. doi:10.1016/j.athoracsur.2004.08.034

[13] Pfannschmidt, J., Hoffmann, H., Muley, T., Krysa, S., Trainer, C. and Dienemann, H. (2002) Prognostic factors for survival after pulmonary resection of metastatic renal cell carcinoma. The Annals of Thoracic Surgery, 74, 16531657. doi:10.1016/S0003-4975(02)03803-1

[14] Calle, E.E., Rodriguez, C., Walker-Thurmond, K. and Thun, M.J. (2003) Overweight, obesity, and mortality from cancer in a prospectively studied cohort of US adults. The New England Journal of Medicine, 348, 1625-1638. doi:10.1056/NEJMoa021423

[15] Lindblad, P., Chow, W.H., Chan, J., et al. (1999) The role of diabetes mellitus in the aetiology of renal cell cancer. Diabetologia, 42, 107-112. doi:10.1007/s001250051122

[16] Setiawan, V.W., Stram, D.O., Nomura, A.M., Kolonel, L.N. and Henderson, B.E. (2007) Risk factors for renal cell cancer: The multiethnic cohort. American Journal of Epidemiology, 166, 932-940. doi:10.1093/aje/kwm170

[17] Zucchetto, A., Dal Maso, L., Tavani, A., et al. (2007) History of treated hypertension and diabetes mellitus and risk of renal cell cancer. Annals of Oncology, 18, 596-600. doi:10.1093/annonc/mdl438

[18] Helmrich, S.P., Ragland, D.R., Leung, R.W. and Paffenbarger, R.S Jr. (1991) Physical activity and reduced occurrence of non-insulin-dependent diabetes mellitus. The New England Journal of Medicine, 325, 147-152. doi:10.1056/NEJM199107183250302

[19] Mokdad, A.H., Ford, E.S., Bowman, B.A., et al. (2003) Prevalence of obesity, diabetes, and obesity-related health risk factors, 2001. The Journal of the American Medical Association, 289, 76-79. doi:10.1001/jama.289.1.76

[20] Landsberg, L. (2005) Insulin resistance and the metabolic syndrome. Diabetologia, 48, 1244-1246. doi:10.1007/s00125-005-1818-Z

[21] Biggs, M.L., Mukamal, K.J., Luchsinger, J.A., et al. (2010) Association between adiposity in midlife and older age and risk of diabetes in older adults. The Journal of the American Medical Association, 303, 2504-2512. doi:10.1001/jama.2010.843

[22] Waalkes, S., Merseburger, A.S., Kramer, M.W., et al. (2010) Obesity is associated with improved survival in patients with organ-confined clear-cell kidney cancer. Cancer Causes Control, 21, 1905-1910. doi:10.1007/s10552-010-9618-2

[23] Schrader, A.J., Sevinc, S., Olbert, P.J., Hegele, A., Varga, Z. and Hofmann, R. (2008) Gender-specific characteristics and survival of renal cell carcinoma. Urologe A, 47, 1182, 1184-1186. doi:10.1007/s00120-008-1832-0

[24] Chow, W.H., Gridley, G., Fraumeni, J.F. Jr. and Jarvholm, B. (2000) Obesity, hypertension, and the risk of kidney cancer in men. The New England Journal of Medicine, 343, 1305-1311. doi:10.1056/NEJM200011023431804

[25] Moyad, M.A. (2001) Obesity, interrelated mechanisms, and exposures and kidney cancer. Seminars in Urologic Oncology, 19, 270-279.

[26] Wolk, A., Gridley, G., Niwa, S., et al. (1996) International renal cell cancer study. VII. Role of diet. International Journal of Cancer, 65, 67-73. 
doi:10.1002/(SICI)1097-0215(19960103)65:1<67::AID-I JC12>3.0.CO;2-F

[27] Wolk, A., Lindblad, P. and Adami, H.O. (1996) Nutrition and renal cell cancer. Cancer Causes Control, 7, 5-18. doi:10.1007/BF00115634

[28] Everhart, J. and Wright, D. (1995) Diabetes mellitus as a risk factor for pancreatic cancer. A meta-analysis. The Journal of the American Medical Association, 273, 1605-1609. doi:10.1001/jama.273.20.1605
[29] Wolf, I., Sadetzki, S., Catane, R., Karasik, A. and Kaufman, B. (2005) Diabetes mellitus and breast cancer. The Lancet Oncology, 6, 103-111. doi:10.1016/S1470-2045(05)01736-5

[30] Constance, S., Sixta, F. and Ostwald, S. (2008) Texas-Mexico border intervention by promotores for patients with type 2 diabetes. The Diabetes Educator, 34, 299-309. doi:10.1177/0145721708314490 